Sādhanā Vol. 37, Part 1, February 2012, pp. 79-88. (C) Indian Academy of Sciences

\title{
Fatigue de-bond growth in adhesively bonded single lap joints
}

\author{
P K SAHOO $^{1, *}$, B DATTAGURU ${ }^{2}, \mathrm{C}^{\text {M MANJUNATHA }}{ }^{1}$ and \\ C R L MURTHY ${ }^{3}$
}

\author{
${ }^{1}$ Structural Technologies Division, CSIR-National Aerospace Laboratories, \\ Bangalore 560017, India \\ ${ }^{2}$ Department of Aerospace Engineering, Jain University, Jakkasandra, \\ Bangalore 560027, India \\ ${ }^{3}$ Department of Aerospace Engineering, Indian Institute of Science, \\ Bangalore 560012, India \\ e-mail: pks@nal.res.in; p_sahoo@hotmail.com
}

\begin{abstract}
The fatigue de-bond growth studies have been conducted on adhesively bonded lap joint specimens between aluminium and aluminium with Redux-319A adhesive with a pre-defined crack of $3 \mathrm{~mm}$ at the bond end. The correlations between fracture parameters and the de-bond growth data are established using both numerical and experimental techniques. In the numerical method, geometrically non-linear finite element analyses were carried out on adhesively bonded joint specimen for various de-bond lengths measured from the lap end along the mid-bond line of the adhesive. The finite element results were post processed to estimate the SERR components $G_{\text {I }}$ and $G_{\text {II }}$ using the Modified Virtual Crack Closure Integral (MVCCI) procedure. In experimental work, specimens were fabricated and fatigue de-bond growth tests were conducted at a stress ratio $R=-1$. The results obtained from both numerical analyses and testing have been used to generate de-bond growth curve and establish de-bond growth law in the Paris regime for such joints. The de-bond growth rate is primarily function of mode-I SERR component $G_{\text {I }}$ since the rate of growth in shear mode is relatively small. The value of Paris exponent $m$ is found to be 6.55 . The high value of de-bond growth exponent in Paris regime is expected, since the adhesive is less ductile than conventional metallic materials. This study is important for estimating the life of adhesively bonded joints under both constant and variable amplitude fatigue loads.
\end{abstract}

Keywords. Lap joint; adhesive bond; FEA; fatigue; MVCCI; de-bond growth.

*For correspondence 


\section{Introduction}

One of the major issues in adhesively bonded joints is the damage tolerance and the long term durability. Aircraft during its operational periods is subjected to fatigue loading. Therefore, its structural components containing such joints experience the fatigue loading and evaluation of these joints is essential in order to study the fatigue behaviour for its safe operation. Even though, there exist numerous amount of literature on static strength evaluation of adhesively bonded joints, there are only a few studies available in the literature on fatigue evaluation of such joints.

Structures are subjected to cyclic-fatigue loads and fail in service. Such fatigue failures can occur even when the maximum cyclic-fatigue loads are well below the static strength of materials. This involves three stages such as crack initiation, crack propagation and final failure. During crack propagation stage the cyclic-fatigue loads produce no crack growth at stress intensity factors lower than the threshold value (figure 1). Fracture mechanics parameters, such as the stress intensity factor, are related to fatigue crack growth. It was experimentally found that for cracked specimens subjected to cyclic loads, the mean value of stress has an important impact on the crack growth rate per cycle. Lin \& Liechti (1987) stated that for adhesively bonded joints, the correlation between de-bond growth rates and the stress intensity factor range has the same sigmoidal shape (Meguid 1989) as the fatigue crack propagation in metals.

Typical FCGR curve shown in figure 1 exhibits three regions. In region I, the existence of a threshold value below which there is no fatigue failure is shown; in region II, the relation between $\log _{10} \frac{\mathrm{d} a}{\mathrm{~d} N}$ and $\log _{10} \Delta K$ is practically linear. Finally, in region III, there is fast crack growth rate. In this region, $K_{\max }$ is close to $K_{\mathrm{c}}$.

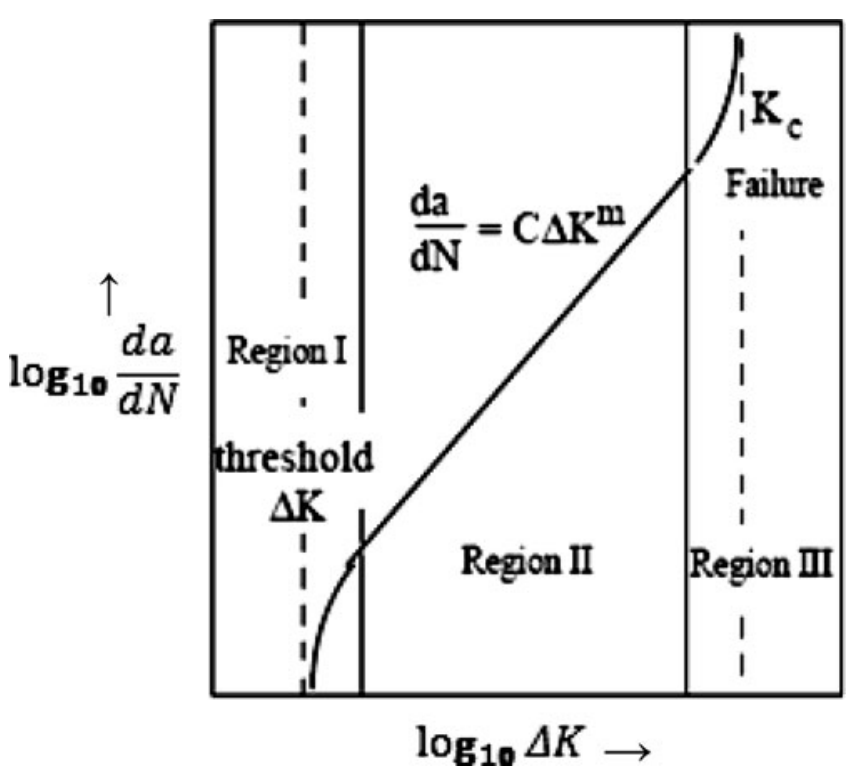

Figure 1. Fatigue crack growth law (Meguid 1989). 
There have been many attempts to model the relation between the fatigue crack propagation rate, $\mathrm{d} a / \mathrm{d} N$, and the stress intensity range. The relation most commonly found in the literature was given by Paris \& Erdogan (1963):

$$
\frac{\mathrm{d} a}{\mathrm{~d} N}=C(\Delta K)^{m},
$$

where $m$ and $C$ are related material-dependent constants. This equation is valid only in region II of the crack growth rate curve and does not take into account the effect of the mean stress. There are several other models for fatigue crack growth (Forman et al 1967; Ewalds \& Wanhill 1984). However, in the present work, the experiments are conducted only at zero mean stress and a correlation will be attempted based on Paris law for de-bond growth and SERR components.

Some of the earlier investigations by Mostovoy \& Ripling (1975) and Brussat et al (1977) involved fatigue studies in adhesively bonded joints. These studies concluded that linear fracture mechanics gives reasonable accuracy in the description of de-bond growth due to fatigue. Dattaguru et al (1984) showed that nonlinearities played an important role in these types of joints.

Lin \& Liechti (1987) correlated de-bond growth rates to strain energy release rates. They found that geometrically nonlinear analysis was needed for the computation of energy release rates. Similarity was found in de-bond growth rate curves for many specimens studied.

Kinloch \& Osiyemi (1993) used a double cantilever beam to correlate experimentally measured crack growth rates with analytically obtained strain energy release rates. A fatigue crack growth rate curve was determined with this data and used for fatigue life prediction of single-lap joint specimens. Good agreement between the predicted and experimental results was found.

In the present investigation, the fatigue crack growth studies have been conducted on adhesively bonded joint specimens between aluminium and aluminium with Redux-319A adhesive with a pre-defined crack of $3 \mathrm{~mm}$ at the bond end. The correlations between fracture parameters and the de-bond growth data are established using both numerical and experimental techniques.

\section{Experimental work}

\subsection{Test specimens}

Fatigue de-bond growth study on adhesively bonded single lap joints with an in-built de-bond of $3 \mathrm{~mm}$ length at lap end (high stress concentration zone) is carried out. The main issue in the fabrication of the specimen here is the introduction of de-bond to study its growth behaviour. The specimen dimensions of the bonded joints considered in this study are as per ASTM D 3165 standard (1997) and the specimen is shown in figure 2. The initial de-bond is also shown in the figure.

\subsection{Fabrication of test specimens}

Aluminium plates of thickness $1.6 \mathrm{~mm}$ are cut into the required sizes of $100 \mathrm{~mm}$ length and $25 \mathrm{~mm}$ width. Aluminium pieces are etched to remove oxides. An adhesive (Redux-319A) film of thickness $0.12 \mathrm{~mm}$ is cut to sizes of $12.7 \mathrm{~mm}$ length and $25 \mathrm{~mm}$ width to match the dimension of the surfaces to be bonded. Firstly, adhesive films of the above sizes are put on the surface of one of the adherent to be bonded. Then a rectangular thin plastic film of size $25 \mathrm{~mm}$ and $3 \mathrm{~mm}$ is put on the top surface of the adhesive from the lap end in order to introduce the de-bond of 


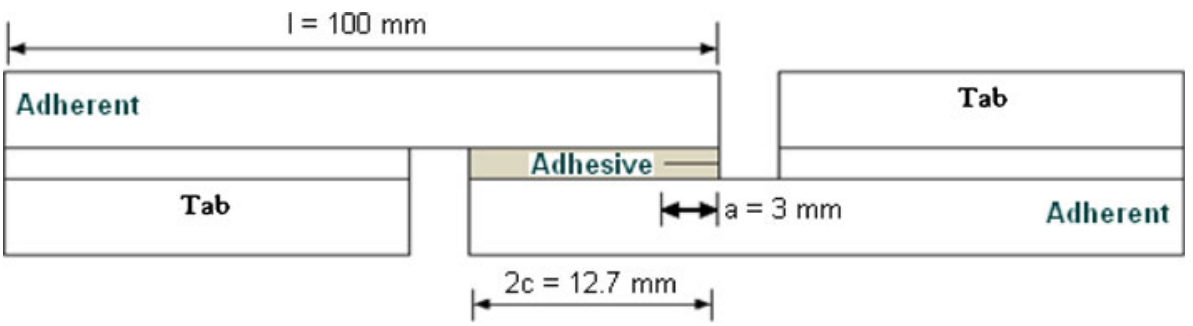

Figure 2. Adhesively bonded single lap joint specimen with de-bond introduced at lap end.

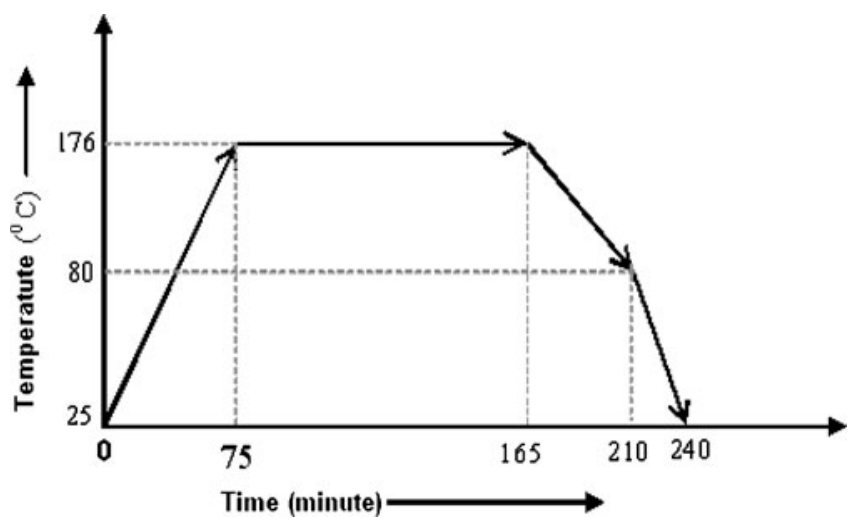

Figure 3. Curing cycle.

$3 \mathrm{~mm}$ length at the lap end. Then other adherent is kept over the adhesive and thin plastic film. The specimens are subjected to a controlled temperature and pressure cycle as per the curing cycle shown in figure 3.

\subsection{Fatigue testing and measurement of de-bond growth}

Fatigue test has been carried out on aluminium to aluminium adhesively bonded single lap joint specimens in order to obtain the crack growth data i.e., de-bond length $(a)$ versus number of cycles $(N)$ data. The tests were performed in a $50 \mathrm{KN}$ computer controlled servo-hydraulic test machine under load control mode applying a sinusoidal load of amplitude $1 \mathrm{kN}$ and stress ratio, $R=\sigma_{\min } / \sigma_{\max }=-1$ at a frequency of $1 \mathrm{~Hz}$, in RT lab air atmosphere (figure 4). Frequency of fatigue loading was kept low in order to avoid thermal effects (Mandell and Meier 1983). The de-bond growth data is obtained until the final failure occurs.

De-bond is filled with liquid dye-penetrant along the mid bond of the joint along which de-bond will be growing. At several stages of its growth, the position of the dye-penetrant is progressively photographed and these stages are marked with the number of cycles of fatigue loading applied till then. It is assumed that the profile of the de-bond front remain straight across the width during its growth and grow in same manner as de-bond as seen from the ends of the width. This method measures de-bond at the ends of joint width. These measurements are carried out at 12 different stages and the variation of de-bond length with the number of cycles is shown graphically in figure 5 . 


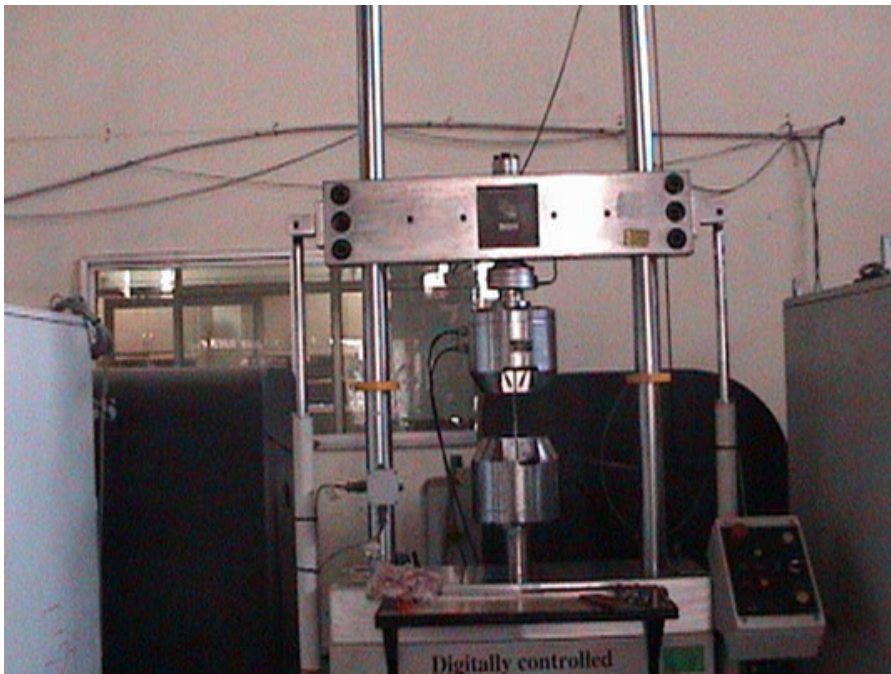

Figure 4. Fatigue test specimen mounted on machine.

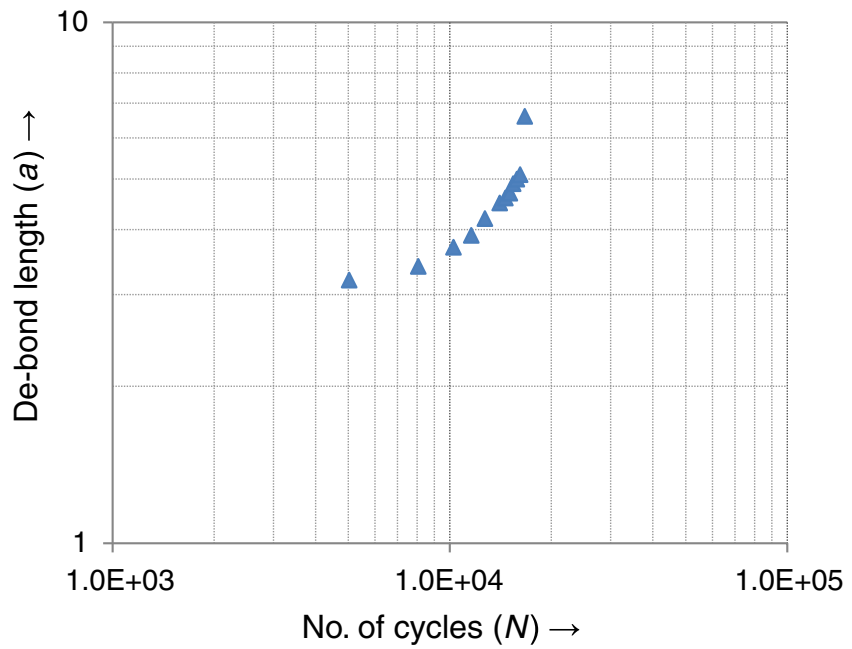

Figure 5. De-bond length versus number of cycles plot.

\section{Numerical modelling and analysis}

The aluminium-aluminium joint with de-bond used for the experimental study is analysed with MSC.NASTRAN finite element analysis code. The geometric non-linear finite element analyses are carried out for different de-bond lengths from $3.7 \mathrm{~mm}$ to $5.1 \mathrm{~mm}$ in steps of $0.2 \mathrm{~mm}$. The finite element mesh details for different de-bond lengths is shown in table 1. The mesh used for this analysis is based on the convergence study carried out by author in an earlier work (Sahoo et al 2007). The finite element mesh for a de-bond length of $4.5 \mathrm{~mm}$ showing displacement 


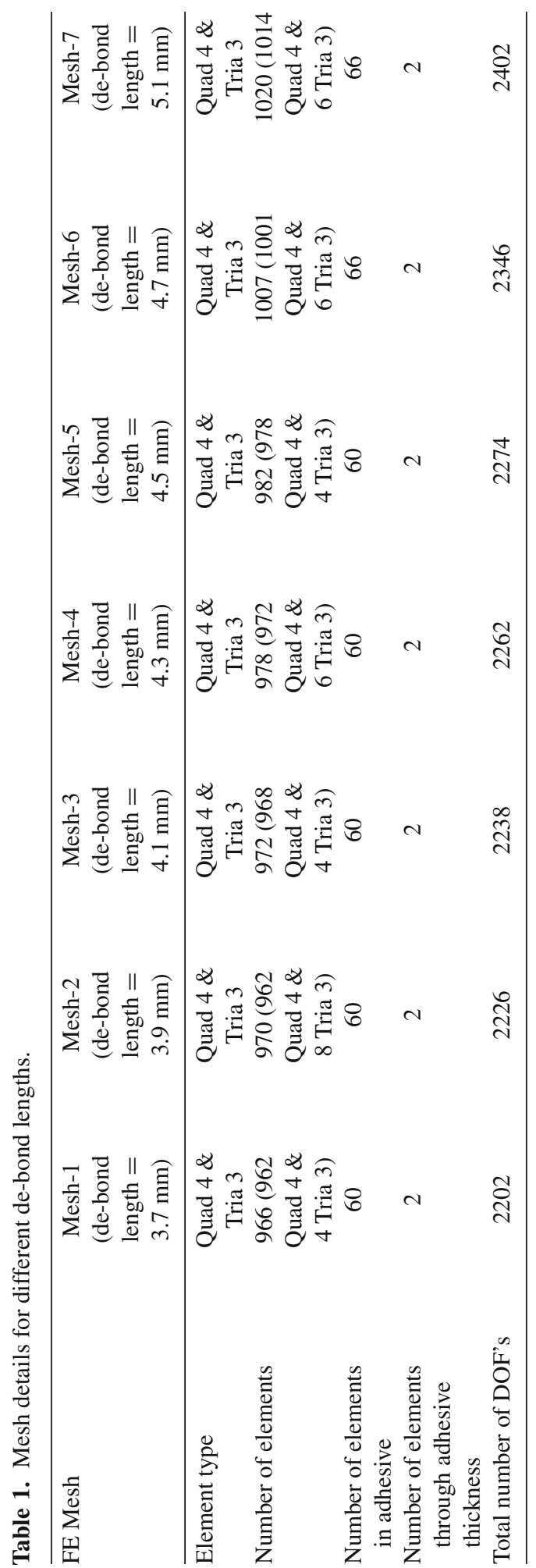



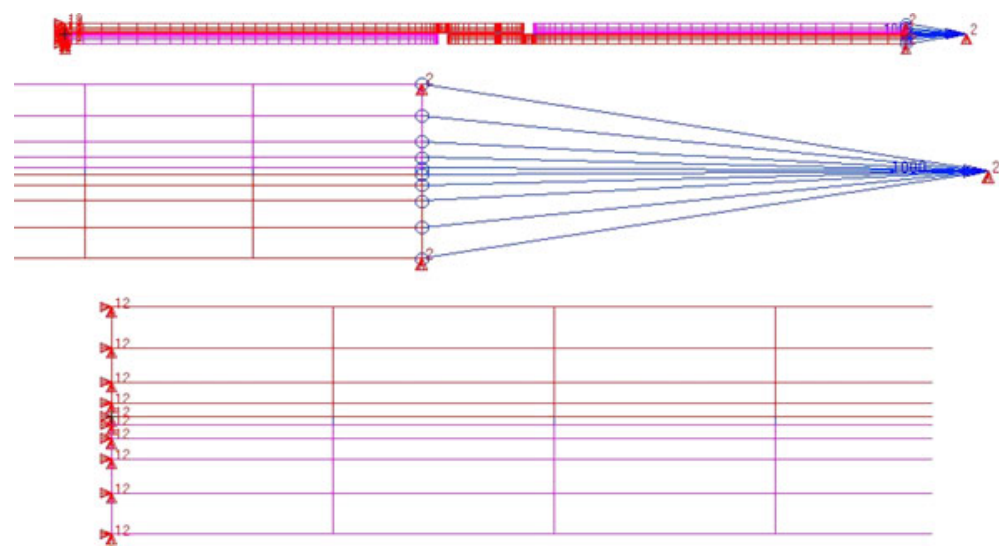

Figure 6. The finite element mesh (for a de-bond length $4.5 \mathrm{~mm}$ ) showing displacement boundary conditions, MPC and load applied.

boundary conditions, Multi-point constraint (MPC) and load applied is shown in figure 6. For seven de-bond lengths from $3.7 \mathrm{~mm}$ to $5.1 \mathrm{~mm}$, the FE mesh is reconstructed and used with NASTRAN. The fracture parameters SERR components are evaluated using MVCCI method (Rybicki \& Kanninen 1977; Ramamurthy et al 1986).

\section{Results and discussion}

\subsection{SERR components variation with de-bond length}

Mode-I and mode-II SERR components $G_{\mathrm{I}}$ and $G_{\mathrm{II}}$ are evaluated from the finite element analysis at various de-bond and this variation is shown in figure 7 . It is seen that the variation of $G_{\text {II }}$ with de-bond length is insignificant over the length. In fact, the variation of mode-II SERR within the de-bond length considered is within $6 \%$. This is because $G_{\text {II }}$ primarily depends on shear load

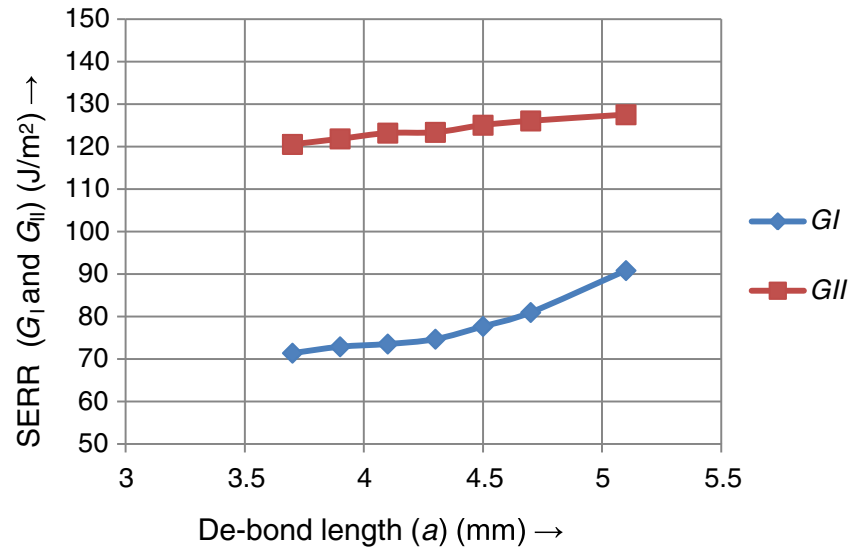

Figure 7. SERR components variation with de-bond length. 
transfer and does not vary significantly with increasing de-bond length. On the other hand, there is an increase in mode-I component as de-bond grows. The effects of peel stress increases with de-bond length. This is significant because the fatigue de-bond growth is primarily dependant on mode-I strain energy release rate.

\subsection{De-bond growth rate}

The de-bond growth rate $\mathrm{d} a / \mathrm{d} N$ is obtained from figure 4 by calculating the slope of the curve following 7 point incremental polynomial method as per ASTM E647-93 standard (1993). The procedure of measurement of slope is: (i) Take first 7 readings of ' $a$ ' versus ' $N$ ' data and draw the $a-N$ curve. (ii) Best fit linear curve out of those data based on linear regression analysis. (iii) The slope of the straight line is corresponding to average slope of first seven de-bond lengths. (iv) The procedure is repeated for subsequent seven points until final $a-N$ data is reached. The de-bond growth rate variation with de-bond length is shown in figure 8 .

\subsection{De-bond length variation with number of cycles}

It is seen from figure 7 that mode-II SERR components has very small variation with de-bond length, whereas there is a significant variation in the mode-I SERR components with de-bond length. Also, observing figure 5, it appears that de-bond growth rate is a primarily function of mode-I SERR component $G_{\text {I }}$ since the variation of $G_{\text {II }}$ with de-bond length is small. This was the observation by several researchers in the past. One of the earliest authors to observe this are Dattaguru et al (1984).

\subsection{Fatigue de-bond growth behaviour}

Figure 7 shows the values of SERR components at various de-bond lengths at the maximum load in the fatigue cycle. These are designated as $G_{\operatorname{Imax}}$ and $G_{\operatorname{IImax}}$, figure 8 shows the de-bond growth rate variation with de-bond length. Using data from figures 7 and 8 , the variation between

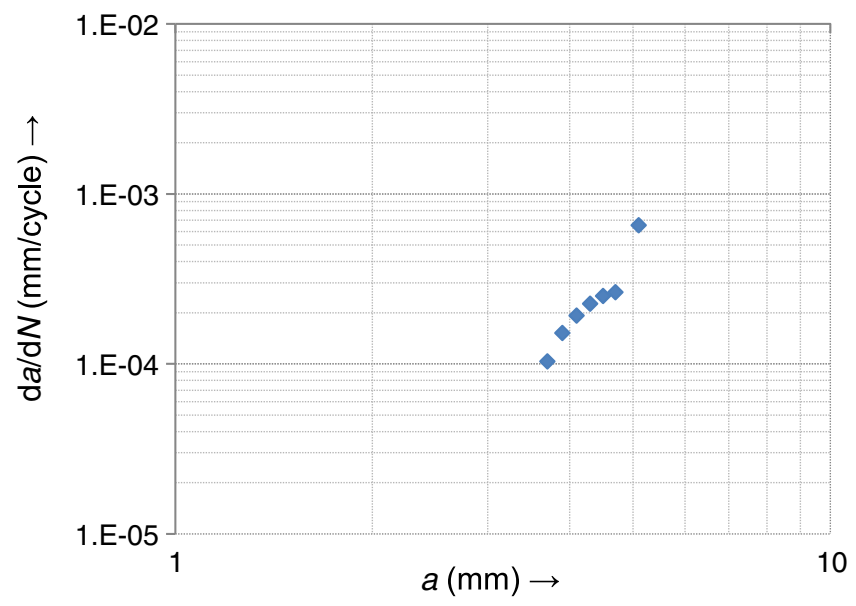

Figure 8. De-bond growth rate versus de-bond length. 


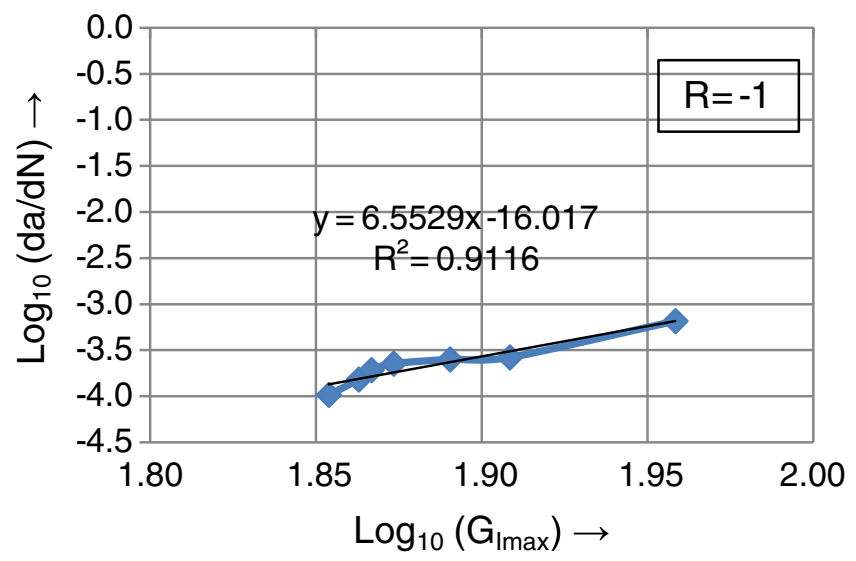

Figure 9. Logarithmic de-bond growth rate variation.

logarithm of $\mathrm{d} a / \mathrm{d} N$ and $\operatorname{logarithm}$ of $G_{\operatorname{Imax}}$ are plotted in figure 9. Following the Paris equation, the de-bond growth is in Paris regime may be expressed as

$$
\frac{\mathrm{d} a}{\mathrm{~d} N}=C G_{\operatorname{Imax}}^{m},
$$

where $C$ and $m$ are material constants corresponding to adhesive material (Redux-319A).

It is observed from figure 9 that the best fit straight line is of the form:

$$
y=6.5529 x-16.017
$$

Comparing equations (2) and (3), the values of Paris exponent $m$ and coefficient $C$ are obtained as: $m=6.55, C=9.62 \mathrm{E}-17$. It may be noted that the values of $m$ and $C$ corresponds to values with respect to the units of $\mathrm{d} a / \mathrm{d} N$ and $G_{\text {Imax }}, \mathrm{mm} /$ cycle and $\mathrm{J} / \mathrm{m}^{2}$ respectively.

Compared to ductile materials for whom the order of Paris exponent $m$ is 4 (HosseiniToudeshky et al 2007) and 'AV119' epoxy adhesive, where the order of exponent is 6 (Curley et al 2000), the order of exponent $m$ equal to 6.55 for an adhesive like Redux-319A which is less ductile than metals appears to be quite acceptable. The equation (1) is required to predict the fatigue de-bond growth life of adhesively bonded joints employing similar adhesive under any arbitrary constant amplitude or variable loading.

In the analysis when de-bond is cohesive, it is assumed at the centre of the bond thickness. In practice, de-bond may initiate at the interface. During the propagation, it goes across the interface and centre of the bond thickness depending on local defects. But, the cohesive failure is analysed with centre line de-bond only.

\section{Conclusions}

Fatigue experiments are carried out on an aluminium-to-aluminium adhesively bonded joint with initial de-bond introduced at lap end. De-bond introduced at the adhesive-adherent interface has been grown leading to cohesive failure. The de-bond length versus number of cycles were obtained experimentally and corresponding SERR components in mode-I and mode-II were obtained using FEA and MVCCI method. Empirical equation similar to that of Paris' for crack 
growth has been obtained using experimental and numerical data. The adhesive being brittle compared to metallic materials, the exponent value obtained is considerably higher and suggest smaller growth lives in such joints. It is also known in many design exercises that they provide very little life for de-bond growth.

Authors PKS and CMM would like to thank the Director, CSIR-National Aerospace Laboratories, Bangalore for encouragement and permitting to publish the work. Dr. Ramesh Sundaram, Scientist, Advanced Composite Division is thanked for his help in fabricating the specimens. Useful discussions held with Dr. V R Ranganath, Scientist, Structural Technologies Division is acknowledged. Colleagues at Structural Integrity Group, Structural Technologies Division and Advanced Composite Division are also thanked.

\section{References}

ASTM D 31651997 Standard test method for strength properties of adhesives in shear by tension loading of single-lap-joint laminated assemblies. Annual Book of ASTM Standards 15.06: 199-202

ASTM E 647-93 1993 Standard test method for measurement of fatigue crack growth rates. Pennsylvania American Society for Testing and Materials, Philadelphia

Brussat T R, Chiu S T, Mostovoy S 1977 Fracture mechanics for structural adhesive bonds-final report AFML-TR-77-163, Air Force Materials Laboratory, Wright-Patterson AFB, Ohio

Curley A J, Hadavinia H, Kinloch A J, Taylor A C 2000 Predicting the service-life of adhesively-bonded joints. Int. J. Fract. 103: 41-69

Dattaguru B, Everett R A Jr, Whitcomb J D, Johnson W S 1984 Geometrically nonlinear analysis of adhesively bonded joints. J. Eng. Mater. Technol. 106: 59-65

Ewalds H L, Wanhill R J 1984 Fracture mechanics. London, UK: Edward Arnold

Forman R G, Kearney V E, Engel R M 1967 Numerical analysis of crack propagation in cyclic-loaded structures. J. Basic Eng, Trans. ASME 89: 459-463

Hosseini-Toudeshky H, Mohammadi B, Bakhshandeh S 2007 Mixed-mode fatigue crack growth of thin aluminium panels with single-side repair using experimental and numerical methods. Fatigue Fract. Eng. Mater. Struct. 30(7): 629-639

Kinloch A J, Osiyemi S O 1993 Predicting the fatigue life of adhesively bonded joints. J. Adhesion 43: 79-90

Lin C, Liechti K M 1987 Similarity concepts in the fatigue fracture of adhesively bonded joints. J. Adhesion 21: $1-24$

Mandell J F, Meier U 1983 Effects of stress ratio, frequency and loading time on the tensile fatigue of glassreinforced epoxy. In: T K O'Brien ed., Long-term behaviour of composites, ASTM STP 813, ASTM International, West Conshohocken, PA, pp. 55-77

Meguid S A 1989 Engineering fracture mechanics. London, UK: Elsevier Science Publishers Ltd.

Mostovoy S, Ripling E J 1975 Flaw tolerance of a number of commercial and experimental adhesives. Adhesion science and technology, L H Lee (ed) 9. B, Plenum Press, NY, pp. 513-562

Paris P C, Erdogan F 1963 A critical analysis of crack propagation laws. J. Basic Eng Trans. ASME 85: 528-534

Ramamurthy T S, Krishnamurthy T, Badari Narayana K, Vijayakumar K, Dattaguru B 1986 Modified crack closure integral method with quarter point elements. Mech. Res. Commun. 13(4): 179-186

Rybicki E F, Kanninen M F 1977 A finite element calculation of stress intensity factor by modified crack closure integral. Eng. Fract. Mech. 9: 931-938

Sahoo P K, Dattaguru B, Manjunatha C M 2007 A parametric study of mixed-mode strain energy release rate components at de-bonds in adhesively bonded composite joints. International and INCCOM-6 conference on future trends in composite materials and processing, IIT Kanpur, India, December 12-14 